\title{
Da colonialidade à decolonialidade: delineando possibilidades para a transformação das relações étnico-raciais e de gênero por meio dos saberes escolares
}

\author{
From coloniality to decoloniality: outlining possibilities to transform ethnic-racial and \\ gender relations through school knowledge
}

\author{
Mariana Alves de Sousa \\ Doutoranda em Educação (UNESP/Marília) \\ ma.sousa@unesp.br \\ Maria Valéria Barbosa \\ Doutora em Ciências Sociais (UNESP/Marília) \\ valeria.barbosa@unesp.br
}

Resumo: O artigo visa problematizar a eurocentrização dos saberes escolares, a partir da contextualização da colonialidade como padrão de poder instituído pela modernidade. Pretende-se apresentar algumas contribuições da pedagogia decolonial para a positivação das relações étnico-raciais e de gênero no ambiente escolar, para além da racionalidade eurocêntrica que lhes é imposta pelo poder hegemônico. A partir da metodologia de pesquisa qualitativa bibliográfica, objetiva-se evidenciar que, embora a sociedade capitalista moderna/colonial esteja permeada pelas contradições entre o estabelecimento de políticas públicas e educacionais e as dificuldades para aplicabilidade das mesmas, os saberes decoloniais e as possíveis confluências se aproximam do propósito político e pedagógico de edificação de uma educação efetivamente democrática.

Palavras-chave: Pedagogia decolonial; Política educacional; Relações étnico-raciais; Relações de gênero.

\begin{abstract}
The article aims to problematize the eurocentrization of school knowledge, based on the contextualization of coloniality as a standard of power instituted by modernity. It is intended to present some contributions from decolonial pedagogy to the positivization of ethnic-racial and gender relations in the school environment, in addition to the Eurocentric rationality imposed on them by the hegemonic power. From the qualitative bibliographic research methodology, the objective is to show that although the modern / colonial capitalist society is permeated by the contradictions between the establishment of public and educational policies and the difficulties for their applicability, decolonial knowledge and possible confluences are close the political and pedagogical purpose of building a democratic education.
\end{abstract}

$\begin{array}{lcr}\text { Keywords: } & \text { Decolonial } & \text { pedagogy; } \\ \text { Educational } & \text { politics; Ethnic-racial } & \text { relations; } \\ \text { Gender } & & \text { relations. }\end{array}$ 


\section{A influência da eurocentrização dos saberes na educação escolar}

Para melhor compreender o processo de eurocentrização dos saberes escolares, torna-se relevante resgatar parte do arsenal teórico que versa sobre processo de instituição do comportamento europeu como parâmetro de poder mundial que incide nas distintas áreas da vida social. Por meio dessas reflexões podem surgir inferências sobre como o apagamento das diversidades étnico-raciais e de gênero, calcado na colonialidade dos saberes, incide nos currículos e práticas escolares e compromete o caráter democrático da educação, apesar da existência de legislações que prezam pela valorização da diversidade e pelo respeito às diferenças.

Para referenciar a crítica à modernidade eurocêntrica, parte-se dos pressupostos teóricos do grupo Modernidade/Colonialidade (M/C), considerando que suas produções podem representar alternativas à construção de uma educação emancipadora. $\mathrm{O}$ referido grupo é formado por intelectuais latino-americanos(as) com diferentes perspectivas teóricas, mas que, comumente, visam construir um projeto "epistemológico, ético e político", suscitando críticas ao padrão hegemônico da modernidade colonial. Autores como Enrique Dussel, Aníbal Quijano, Walter Mignolo, Ramón Grosfoguel, Catherine Walsh, Nelson Maldonado-Torres, Arturo Escobar e, ainda, o sociólogo norteamericano Immanuel Wallerstein integram o grupo (OLIVEIRA; CANDAU, 2010: 1617).

Luiz Fernandes de Oliveira e Vera Maria Ferrão Candau (2010) enfatizaram que o grupo parte do princípio de que a colonialidade é parte integrante da modernidade. Em outras palavras, a partir do processo de colonização, a Europa se constituiu como modelo universal na produção de conhecimentos. Tal lógica vem promovendo o apagamento de outras formas de saberes, tendo como esteio a colonialidade. Esta, por sua vez, é complementar ao colonialismo para Aníbal Quijano (2007), embora atuem de formas diferentes. Para este autor, o colonialismo corresponde a uma estrutura de dominação e exploração de:

[...] controle da autoridade política, dos recursos de produção e do trabalho de uma população determinada possui uma diferente identidade e as suas sedes centrais estão, além disso, em outra jurisdição territorial. [...] $\mathrm{O}$ colonialismo é, obviamente, mais antigo; no entanto, a colonialidade provou 
ser, nos últimos 500 anos, mais profunda e duradoura que o colonialismo. Porém, sem dúvida, foi forjada dentro deste, e mais ainda, sem ele não teria podido ser imposta à [sic] inter-subjetividade de modo tão enraizado e prolongado (QUIJANO, 2009: 73).

Mais do que isso, Quijano (2005) apontou que a constituição da América como parte do processo de globalização produziu identidades "historicamente novas", isto é, as identidades dos povos colonizados: negros, indígenas, mestiços, dentre outros. Dessa forma, o projeto colonial contribuiu para o recrudescimento da ideia de dominação a partir da hierarquização das diferentes identidades, produzindo lugares e papéis sociais inferiorizados como um padrão de comportamento. Assim, a categoria de raça passou a atuar como uma "construção mental", um engodo da "superioridade branca" em que se baseia o exercício fundamental da "dominação colonial", reproduzida a partir das perspectivas que instituem o eurocentrismo como única forma de racionalidade e padrão de comportamento (QUIJANO, 2005: 117).

De acordo com Jean-Paul Sartre, as análises que Frantz Fanon (1968) elaborou sobre o colonialismo em sua obra "Condenados da Terra" evidenciam aspectos que o liberalismo oculta sobre o processo colonizador por meio das ideias de liberdade e igualdade. Para Sartre (1968: 09), a burguesia passou a considerar a população colonizada como pertencentes "a sua espécie" a partir do momento em que se tornaram livres: "se não fossem homens e livres, como poderiam vender livremente sua força de trabalho?". Desse modo, o colonialismo atuava de modo a inferiorizar a população das colônias para justificar a hierarquia dos colonos. "A violência colonial não tem somente o objetivo de garantir o respeito desses homens subjugados; procura desumanizá-los. Nada deve ser poupado para liquidar suas tradições, para subtrair a língua [...], para destruir sua cultura [...]" (SARTRE, 1968: 09).

Colonialismo denota uma relação política e econômica, na qual a soberania de um povo reside no poder de outro povo ou nação, o que constitui a tal nação em um império. Diferente desta ideia, a colonialidade se refere a um padrão de poder que emergiu como resultado do colonialismo moderno, mas que em vez de estar limitado a uma relação formal de poder entre dois povos ou nações, se refere à forma como o trabalho, o conhecimento, a autoridade e as relações intersubjetivas se articulam entre si através do mercado capitalista mundial e da ideia de raça. Assim, apesar do colonialismo 
preceder a colonialidade, a colonialidade sobrevive ao colonialismo. Ela se mantém viva em textos didáticos, nos critérios para o bom trabalho acadêmico, na cultura, no sentido comum, na autoimagem dos povos, nas aspirações dos sujeitos e em muitos outros aspectos de nossa experiência moderna. Neste sentido, respiramos a colonialidade na modernidade cotidianamente (MALDONADO-TORRES, 2007: 131, tradução nossa) ${ }^{1}$.

Assim, é possível considerar que o eurocentrismo representa uma das formas pela qual o colonialismo imprimiu suas marcas por meio da colonialidade. Consequentemente, o apagamento da história dos povos colonizados contribui para a perpetuação da inferiorização de suas identidades e produz a percepção de não pertencimento, que pode ser entendida como contrária a qualquer projeto democrático.

Ainda que o projeto de dominação da colonialidade se manifeste na eurocentrização dos saberes, políticas educacionais regulamentam a educação brasileira de forma que as diferenças e diversidades sejam abordadas no contexto escolar, contrariamente à expressão de uma forma única de saber. De acordo com o Art. $3^{\circ}$ da Lei de Diretrizes e Bases da Educação Nacional - LDB (1996), o pluralismo de ideias e concepções pedagógicas é parte dos princípios da educação. Em relação às disposições gerais da Educação Básica, a legislação estabelece ainda que:

Art. 26. Os currículos do ensino fundamental e médio devem ter uma base nacional comum, a ser complementada, em cada sistema de ensino e estabelecimento escolar, por uma parte diversificada, exigida pelas características regionais e locais da sociedade, da cultura, da economia e da clientela.

$\S 4^{\circ} \mathrm{O}$ ensino da História do Brasil levará em conta as contribuições das diferentes culturas e etnias para a formação do povo brasileiro,

\footnotetext{
${ }^{1}$ Colonialismo denota una relación política y económica, en la cual la soberanía de un pueblo reside en el poder de otro pueblo o nación, lo que constituye a tal nación en un imperio. Distinto de esta idea, la colonialidad se refiere a un patrón de poder que emergió como resultado del colonialismo moderno, pero que en vez de estar limitado a una relación formal de poder entre dos pueblos o naciones, más bien se refi ere a la forma como el trabajo, el conocimiento, la autoridad y las relaciones intersubjetivas se articulan entre sí, a través del mercado capitalista mundial y de la idea de raza. Así, pues, aunque el colonialismo precede a la colonialidad, la colonialidad sobrevive al colonialismo. La misma se mantiene viva en manuales de aprendizaje, en el criterio para el buen trabajo académico, en la cultura, el sentido común, en la auto-imagen de los pueblos, en las aspiraciones de los sujetos, y en tantos otros aspectos de nuestra experiencia moderna. En un sentido, respiramos la colonialidad en la modernidade cotidianamente.
} 
especialmente das matrizes indígena, africana e europeia (BRASIL, 1996: 9$10)$.

Sobre esse contexto, o Movimento Negro foi e segue sendo um potente aliado para a construção de uma educação democrática, que reconheça as desigualdades e valorize as diferenças. De acordo com Petronilha Silva (2007), diante das as ações do Movimento Negro para o reconhecimento e superação das desigualdades estruturais e discriminações que acometem a população negra historicamente, o Conselho Nacional de Educação (CNE) determinou a alteração da LDB pela Lei Federal 10.639/03, para incluir obrigatoriamente a temática sobre "História Africana e Afro-brasileira" no currículo oficial da Rede de Ensino. Cinco anos após a promulgação da referida Lei, o ensino sobre a história e cultura indígena passou a figurar também como obrigatório, com a promulgação da Lei 11.645/08.

No processo de orientações para a execução da legislação, houve discussões sobre a educação para as relações étnico-raciais, envolvendo o debate acerca da formação de professoras(es) sobre a temática e o estabelecimento da carga horária de conteúdos que pudessem aprofundar a discussão e torná-la regular no contexto escolar. Contudo, ao passo que surgem avanços progressistas nas políticas educacionais, também surgem alguns desafios para a aplicabilidade delas.

A exemplo disso, podemos citar o veto do artigo 79-A da Lei 10.639/03. Este artigo estabelecia que os cursos de capacitação de professores(as) fossem ministrados por membros do Movimento Negro, universitários(as) pesquisadores(as) das temáticas étnico-raciais ou integrantes de outras instituições que pautam o assunto. ${ }^{2} \mathrm{O}$ veto ocorreu com justificativa baseada no artigo 26 da Lei $n^{\circ}$ 9.394/1996, que determina que: “os currículos de ensino fundamental e médio devem ter uma base nacional comum a ser complementada, em cada sistema de ensino ou estabelecimento escolar, por uma parte diversificada, exigida pelas características regionais e locais da sociedade, da cultura, da economia e da clientela" (BRASIL, 1996).

Da mesma forma, o $3^{\circ}$ caput também foi vetado ${ }^{3}$, deixando de exigir que dez por cento das disciplinas de História do Brasil e Educação Artística no Ensino Médio

\footnotetext{
2 Art. 79-A, acrescido pelo projeto à Lei no 9.394/1996. “Os cursos de capacitação para professores deverão contar com a participação de entidades do movimento afro-brasileiro, das universidades e de outras instituições de pesquisa pertinentes à matéria".

3 Legislação Informatizada - Lei $\mathrm{n}^{\mathbf{o}}$ 10.639, de 9 de janeiro de 2003 - veto. Disponível em: https://www2.camara.leg.br/legin/fed/lei/2003/lei-10639-9-janeiro-2003-493157-veto-13762-pl.html. Acesso em: 26 nov. 2020.
} 
fossem destinadas à abordagem sobre a temática. Nesse contexto se configurou a política curricular que estabelece relações e conflitos no âmbito da educação de brasileiros(as) de distintas origens étnico-raciais, de modo que as desvantagens atingem significativamente à população negra, mas prejudicam também a população indígena (HENRIQUES, 2001; JACCOUD, 2002; PAIXÃO, 2006 apud SILVA, 2017: 490).

Ao passo que os cursos de capacitação de professores(as) dispensam a participação de agentes políticos do Movimento Negro e demais instituições, a educação para as relações étnico-raciais é negligenciada, pois o trato da temática requer profundo entendimento sobre os aspectos históricos, políticos e sociais que a envolve. Em outras palavras, a participação prioritária dos referidos agentes nos cursos de formação de professores(as) seria substancial para a elaboração de metodologias e práticas educacionais efetivas sobre as relações étnico-raciais.

Mesmo que a diversidade e as diferenças culturais e étnicas estejam previstas no currículo da Educação Básica, na prática esses aspectos se manifestam de forma inconsistente. Para Catherine Walsh (2009), ao admitir o eurocentrismo como única forma de conhecimento, a colonialidade dos saberes desqualifica e deslegitima outras racionalidades epistêmicas. Consequentemente, tal forma de poder contribui para o silenciamento das narrativas e para o apagamento das diferentes formas de existência e saberes.

O ocultamento da diversidade produz a imagem do brasileiro cordial, que trata a todos com igualdade, ignorando deliberadamente as suas nítidas e contundentes diferenças. Imagem esta difundida desde os anos 1930 nas obras de Freyre (1963) e nos anos 1950, reforçada pelas teses, argumentos, estudos, entre outros de Cassiano Ricardo (1959). Tais pensamentos têm constrangido a participação nos espaços públicos daqueles chamados de excluídos, e ao mesmo tempo têm atribuído sua ausência à pretendida falta de qualidades e competência (SILVA, 2007: 499).

Como bem observou Petronilha Silva (2007), a irregularidade do debate sobre a diversidade produz aos grupos racializados como negros e indígenas, o sentimento de não pertencimento social. Perspectivas equivocadas sobre as relações étnico-raciais reforçam a concepção de que não há conflitos entre os diferentes grupos raciais, pois as diferenças são ignoradas. Considerando a diversidade dos sujeitos que integram o 
contexto escolar, negligenciar esse debate pode comprometer o processo de formação cidadã, dentre outras consequências que podem refletir na construção identitária dos(as) educandos(as).

É possível considerar que a marca do colonialismo nos currículos escolares se manifesta, portanto, a partir do apagamento das Histórias e Culturas Afro-Brasileiras e Indígenas, ainda que haja leis e diretrizes que propõem o contrário. Ao relacionarmos as críticas do grupo Modernidade/Colonialidade (M/C) aos entraves que os saberes e práticas decoloniais são submetidos para se efetivarem nos currículos escolares, torna-se possível inferir que, assim como os povos indígenas, africanos e afro-brasileiros foram inferiorizados pelo colonialismo, suas histórias e culturas também assumiram o mesmo destino. Este processo pode ser compreendido como mais uma das formas pela qual o padrão do colonialismo perpetua o sentimento de inferioridade e retroalimenta sua expressão de dominação. Como consequência, a "educação moderno-colonialpatriarcal" reproduz a desumanização daqueles(as) que vivenciam o processo de racialização na perspectiva hierárquica imposta pelo colonialismo e pela colonialidade que a ele é inerente (FERREIRA; SILVA, 2018: 87). "A nossa compreensão ou compreensões de currículo estão circunscritas aos pensamentos eurocentrados e, por conseguinte, o que habita o território cultural epistêmico do currículo também passa pelas lentes seletivas e classificatórias do colonizador, ou seja, lentes da ciência colonizadora travestida de neutralidade" (FERREIRA; SILVA, 2018: 81).

Ferreira e Silva (2018) admitem que o currículo colonizado e colonizador se baseia na racionalidade eurocêntrica como única perspectiva de saber. A esse fato, Mignolo atribui a explicação de que a expansão ocidental posterior ao século XVI não foi apenas econômica e religiosa, mas também se impôs sobre as formas de conhecimento hegemonicamente, estabelecendo-se como padrão epistêmico, político e historiográfico e definindo o que constitui a colonialidade do saber. Nesse sentido, a colonialidade do saber produz não somente a negação do conhecimento dos povos subjugados pelo colonialismo, mas a negação da humanidade desses povos, ou seja, a colonialidade do ser (OLIVEIRA; CANDAU, 2010). "A colonialidade do ser é pensada, portanto, como uma negação do estatuto humano para africanos e indígenas, por exemplo, na história da modernidade colonial. Essa negação, segundo Walsh (2006), implanta problemas reais em torno da liberdade do ser e da história do indivíduo subalternizado por violência epistêmica” (OLIVEIRA; CANDAU, 2010: 22). 
Grada Kilomba (2019: 12) ressalta a importância de elaborar um "processo de conscientização coletiva", pois a "glorificação da história colonial" que se constitui a partir da negação de humanidades e de outros saberes impede a criação de novas histórias e conhecimentos. Assim, considera-se que é no processo de conscientização coletiva que os sujeitos com identidades marginalizadas adquirem condições para reconfigurar sua noção de conhecimento e suas formas de existência, para além das imposições do padrão colonial.

Para Oliveira e Candau (2010: 24), a decolonialidade propõe uma estratégia de "reconstrução radical do ser, do poder e do saber". Em outras palavras, a decolonialidade consiste em visibilizar as lutas contra a colonialidade a partir dos sujeitos, ou seja, aqueles que adquirem consciência da história e "o direito de definir suas próprias realidades, estabelecer suas próprias identidades e nomear suas histórias" (HOOKS, 1989: 42 apud KILOMBA, 2019: 28) ${ }^{4}$. Portanto, torna-se necessário reconhecer as possibilidades de (re)existência que a decolonialidade apresenta, na medida em que propõe que a desumanização imposta pelo colonialismo e pela colonialidade seja um ponto de partida para desvelar os interesses que se constituíram ao longo desses processos, considerando as lutas dos povos subalternizados travadas como estratégias de resistência.

É importante considerar que a diversidade a qual as políticas educacionais devem valorizar também envolve as questões de gênero. Nesse sentido, deve-se ponderar que as pessoas negras e indígenas são dotadas de identidade étnico-racial, mas não somente. Tais identidades apresentam aspectos de gênero que, em uma perspectiva interseccional e democrática, devem ser considerados (GOMES, 2003). Sendo assim, é relevante destacar que se os fenômenos sociais das desigualdades e diferenças étnicoraciais e de gênero integram a sociedade, estes também se manifestam nos espaços de formação escolar, quando consideramos que neste espaço, assim como na sociedade, a diversidade se faz presente.

O Estatuto da Juventude, instituído em 2013 pela Lei n ${ }^{\circ}$ 12.852/2013, determina que os direitos dos(as) jovens devem ser garantidos e promovidos pelo Estado. Dentre esses direitos, o documento versa sobre o Direito à Diversidade e à Igualdade.

\footnotetext{
${ }^{4}$ Kilomba (2019) utilizou a referência de bell hooks (1989) Talking back: thinking feminist, talking black. Traduzido para o português como "Erguer a voz: pensar como feminista, pensar como negra".
} 
Entretanto, em 2015, foi aprovada e sancionada a Lei Municipal 1.516/2015 no Município de Nova Gama, Goiás, visando proibir materiais com "informações de ideologias de gênero" nas escolas do município. Em 2020, o Supremo Tribunal Federal (STF) divulgou ${ }^{6}$ a inconstitucionalidade da referida lei, declarada pelo Plenário. Com base no Estatuto da Juventude, a eliminação das temáticas de gênero dos currículos escolares contribui para o recrudescimento das desigualdades e comprometem o direito à diversidade das juventudes.

Uma vez que a colonialidade atinge todas as áreas da vida social, as relações de gênero também são atingidas por aspectos de dominação e hierarquização. Em outras palavras, o padrão de poder colonial também estabelece a universalização da categoria de gênero, de modo a desconsiderar os múltiplos aspectos que a envolve.

Diferentemente da colonização, a colonialidade do gênero ainda está conosco; é o que permanece na intersecção de gênero/classe/raça como construtos centrais do sistema de poder capitalista mundial. Pensar sobre a colonialidade do gênero permite-nos pensar em seres históricos compreendidos como oprimidos apenas de forma unilateral (LUGONES, 2014: 939).

Portanto, ainda que as Leis Federais 10.639/03 e 11.645/08 e o Estatuto da Juventude representem um avanço do ponto de vista das políticas públicas e educacionais, é possível considerar que a perpetuação da colonialidade interfere na efetivação de práticas de ensino e aprendizagem que possam emancipar a formação dos(as) educandos(as), considerando suas diversidades enquanto sujeitos e cidadãos(ãs).

A deturpação da temática de gênero como uma "falácia de ideologia" que poderia corromper a moral da família tradicional (REIS; EGGERT, 2017), criada para mobilizar a retirada do debate dos currículos escolares, também pode ser compreendida como uma estratégia de controle derivada da colonialidade. A universalização da categoria de gênero também pode ser favorável ao padrão hegemônico, na medida em que desconsidera as outras formas de ser que não são baseadas no "cisheteropatriarcado branco e de base europeia" (AKOTIRENE, 2019).

\footnotetext{
${ }^{5}$ Lei declarada inconstitucional pelo Supremo Tribunal Federal (STF) "proíbe material com informações de ideologia de gênero nas escolas municipais de Nova Gama, no estado de Goiás. Disponível em: https://acessoainformacao.novogama.go.gov.br/legislacao/lei/id=49. Acesso em: 27 nov. 2020.

6 Lei municipal que proíbe ensino sobre questões de gênero é inconstitucional. Disponível em: http://www.stf.jus.br/portal/cms/verNoticiaDetalhe.asp?idConteudo=442331. Acesso em: 26 nov. 2020.
} 
O patriarcado é um sistema político modelador da cultura e dominação masculina, especialmente contra as mulheres. É reforçado pela religião e família nuclear que impõem papéis de gênero desde a infância baseados em identidades binárias, informadas pela noção de homem e mulher biológicos, sendo as pessoas cisgêneras aquelas não cabíveis, necessariamente, nas masculinidades e feminilidades duais hegemônicas (AKOTIRENE, 2019: $67)$.

Carla Akotirene (2019) pontua que a interseccionalidade é um instrumento teórico-metodológico que amplia a percepção sobre como as múltiplas formas de opressão se entrecruzam e tal compreensão potencializa o enfrentamento a elas. Compreendendo a interseccionalidade como uma metodologia que possibilita confluências com a decolonialidade, é relevante utilizá-la como uma das estratégias para estabelecer, no campo educacional, questionamentos e transformações da colonialidade dos saberes em suas diversas perspectivas.

Diante de tais contradições, a descolonização dos saberes e das práticas educativas pode ser uma alternativa para a superação gradual das heranças do colonialismo - a colonialidade. Portanto, a elaboração de pesquisas acerca de políticas públicas e educacionais não pode prescindir das reflexões sobre as consequências da colonialidade dos saberes nos currículos escolares para que, a partir disso, seja possível pontuar limites e possibilidades para que o processo de ensino e aprendizagem seja construído em uma perspectiva libertadora e, portanto, decolonial.

\section{As contribuições da pedagogia decolonial para a descolonização dos saberes escolares acerca das categorias de raça e gênero}

Conforme apresentado na seção anterior, as temáticas que discutem as categorias de raça e gênero no ambiente escolar são alvo de redução de carga horária ou retirada dos currículos escolares. Pode-se considerar que tais medidas inviabilizam que os saberes escolares possam ser emancipadores, uma vez que não preconiza outras epistemologias que permitam o resgate da historicidade das categorias de raça e gênero, para além dos parâmetros da racionalidade colonial. Diante disso, esta parte do artigo pretende apresentar perspectivas teóricas que possam vir a mobilizar a elaboração de 
práticas de ensino a fim de desnaturalizar o padrão eurocêntrico que incide sobre as referidas categorias.

Para problematizar a inconsistência do debate étnico-racial e de gênero em sua perspectiva decolonial nos currículos escolares, estabelece-se como ponto de partida a seguinte indagação: como efetivar a construção de saberes fundamentados em bases teóricas e epistemológicas não-eurocêntricas em uma realidade na qual os enfoques teóricos adotados por parte expressiva de docentes têm como pressuposto o padrão moderno colonial? É possível considerar que o impasse epistemológico surge diante de uma série de interesses políticos e ideológicos que conflitam a sociedade e o Estado, dentre eles a perspectiva de que a realização do debate teórico acerca da diversidade e das diferenças, sob um viés decolonial, atua como tentativa de construir uma nova interpretação da história do Brasil e fragilizar a identidade nacional (OLIVEIRA; CANDAU, 2010: 33).

A princípio, para nutrir a efetivação de práticas e saberes contrários à racionalidade europeia, considera-se fundamental reconhecer na pedagogia decolonial a possibilidade de ruptura com os padrões de saberes hegemônicos, bem como afirmar nela a produção de metodologias "em contextos de marginalização, resistência e que Adolfo Albán tem chamado de 're-existência'; pedagogias como práticas insurgentes que fraturam a modernidade/colonialidade e tornam possível outras formas de ser, estar, pensar, saber, sentir, existir e viver-com" (WALSH, 2003: 19 apud ADAMS, 2015: $585)$.

Para tanto, é importante pontuar que a privação dos conteúdos acerca das relações étnico-raciais e de gênero nos currículos escolares é prejudicial tanto para o caráter democrático das políticas educacionais, quanto para a afirmação da diversidade dos(as) educandos(as), implicando na redução de suas existências a meros objetos no processo de ensino e aprendizagem. 'bell hooks usa esses dois conceitos de 'sujeito' e ‘objeto' [...]. Como objetos, no entanto, nossa realidade é definida por outros, nossas identidades são criados por outros, e nossa 'história designada somente de maneira que definem (nossa) relação com aqueles que são sujeitos"” (hooks, 1989: 42 apud KILOMBA, 2019: 28).

Diante da circunstância em que os conteúdos que abordam a realidade dos(as) educandos(as) de forma diversificada sofrem de apagamento no contexto escolar, podese considerar que os(as) estudantes são reduzidos à posição de objeto, devido ao fato de não se apropriarem das narrativas sobre suas histórias para além do viés da 
racionalidade eurocentrada. Assim, a educação escolar assume um caráter de “conformação" e de "consolidação" (FERREIRA; SILVA, 2018: 87) da inferiorização dos indivíduos subalternizados na lógica da racionalidade moderna/colonial.

bell hooks (2013) mencionou que seus conhecimentos adquiridos a partir da experiência como educadora, pesquisadora e na vivência como mulher negra, evidenciaram que a educação tem um teor político para a população negra - pode-se dizer que para as demais populações inferiorizadas também. A partir da apropriação e da prática de uma pedagogia engajada, crítica e libertadora, a educação tem o potencial de "nutrir o intelecto" e atuar como estratégia contra-hegemônica de resistir aos eixos da colonialidade (hooks, 2013:10).

É possível inferir que, na medida em que bell hooks reconheceu a potencialidade da sua identidade enquanto mulher negra socialmente, considerando que sua realidade é tangenciada por, no mínimo, dois marcadores sociais da diferença - a raça e o gênero -, também reconheceu o potencial de seu papel enquanto educadora em prol de uma educação libertadora.

Diante dessa perspectiva, é importante pontuar a tendência que os espaços de deliberação e construção política - como os movimentos sociais ou os espaços de produção de conhecimentos formais e não-formais -, possuem de omitir o debate sobre as diferenças raciais e de gênero. Aparentemente, esse "esquecimento" é reflexo tanto da preconização do debate econômico como sendo o maior determinante das desigualdades, quanto das impressões que o colonialismo produziu a partir da colonialidade, de modo a manter em contexto de inferiorização aqueles grupos que, historicamente, foram subalternizados.

Em suas interpretações sobre as articulações e ações do movimento feminista do Brasil dos anos 80, Lélia Gonzalez (2018) enfatiza e problematiza o esquecimento da pauta racial.

Temos um exemplo de definição do feminismo: 'consiste na resistência de mulheres em aceitar papéis, situações sociais, econômicas, políticas, ideológicas e características psicológicas que tenham como fundamento a existência de uma hierarquia entre homens e mulheres, a partir da qual a mulher é discriminada' (Astelarra). Bastaria substituir os termos homens e mulheres por brancos e negros (ou índios), respectivamente, para ter uma excelente definição de racismo. Exatamente porque tanto o racismo, quanto o feminismo partem das diferenças biológicas para estabelecerem-se como 
ideologias de dominação. Cabe, então, a pergunta: como se explicaria esse esquecimento por parte do feminismo? A resposta, na nossa opinião, está no que alguns cientistas sociais caracterizam por racismo por emissão e cujas raízes, dizemos nós, se encontram em uma visão de mundo eurocêntrica e neocolonialista da sociedade (GONZALEZ, 2018: 309) ${ }^{7}$.

Lélia, enquanto intérprete brasileira e uma das fundadoras do Movimento Negro Unificado - MNU (1978), analisou criteriosamente a forma com que o padrão moderno colonial se manifesta até mesmo nos contextos de luta por igualdade e justiça social. Em sua defesa por um feminismo afrolatinoamericano, mesmo sem fazer referência à metodologia interseccional, a autora admitiu esse viés para problematizar tanto a ausência do debate racial no movimento feminista, quando a presença do sexismo no movimento negro.

Para Lélia, a conscientização da opressão para as $\operatorname{amefricanas~}^{8}$ e ameríndias ocorre a partir do marcador racial. A exploração de classe e o racismo são aspectos em comum da luta de mulheres e homens negros e indígenas, tendo como ponto de partida a experiência da escravização e das formas "político-culturais de resistência" que hoje nos mobilizam a prosseguir a luta pela emancipação. Por esse motivo, Lélia destacou que a presença de mulheres nos movimentos étnicos e raciais é fundamental para fortalecer a luta; contudo, são nesses espaços que surge a consciência do sexismo que produz a exclusão do público feminino nos espaços de decisões políticas.

[...] é justamente a consciência objetiva desse racismo sem disfarces e o conhecimento direto de suas práticas cruéis que despertam esse empenho, no sentido de resgate e afirmação da humanidade e competência de todo grupo étnico considerado 'inferior'. A dureza do sistema fez com que a comunidade negra se unisse e lutasse, em diferentes níveis, contra todas as formas de opressão racistas. Já nas sociedades de racismo por degeneração [...] a força cultural apresenta-se como a melhor forma de resistência. O que

\footnotetext{
${ }^{7}$ O artigo de Lélia Gonzalez intitulado "Por um feminismo afrolatinoamericano" foi originalmente publicado na Revista Isis Internacional, Santiago, v. 9: 133-141, 1988.

${ }^{8}$ Categoria político-cultural que Lélia Gonzalez utilizou para se referir às mulheres africanas, negras, indígenas e/ou descendentes que residem na América Latina.
} 
não significa que vozes solitárias não se ergam, efetuando análisesdenúncias do sistema vigente (GONZALEZ, 2018: 327) 9 .

A forma com que Lélia evidenciou o esquecimento da questão racial pelo feminismo de sua época, bem como a forma com que expressou seu incômodo com o sexismo vivenciado com seus companheiros do MNU, também representa uma forma de ampliar o debate decolonial por meio dos saberes escolares. Nessa perspectiva, o estabelecimento das temáticas sobre diversidade e diferenças nos currículos escolares não ameaça a identidade nacional, tendo em vista que esta noção apenas representa mais uma das nuances pela qual o colonialismo se perpetua nas áreas básicas da vida social.

Para tanto, faz-se oportuno refletir sobre como os processos educacionais podem representar uma contrapartida às epistemologias eurocêntricas que invisibilizam as questões de raça e gênero. Walsh (2006) apresenta algumas possibilidades baseadas na decolonialidade e no pensamento crítico. Baseando-se na historiografia de movimentos sociais indígenas equatorianos e afro-equatorianos, a autora considera que a decolonialidade parte do contexto de desumanização, exploração e/ou invisibilidade para evidenciar outras formas de ser, poder e saber provenientes das lutas de resistência dos povos historicamente subalternizados (OLIVEIRA; CANDAU, 2010: 24).

No contexto da produção de saberes, o exercício da decolonialidade dos saberes também se mostra necessário, a partir do exposto, por exemplo, na leitura de Lélia Gonzalez sobre o movimento feminista e o movimento negro diante do racismo e do sexismo. A proposta de movimento étnico que o feminismo pautado na amefricanidade representa é, evidentemente, uma forma de existir e (re)existir, para além das determinações do padrão da modernidade colonial e patriarcal. Referências como estas podem propiciar aos(às) educandos(as) a compreensão de que os povos africanos, negros, indígenas, bem como as mulheres, não são essencialmente inferiores, mas foram inferiorizados para fazer valer a lógica de dominação colonial, que, por sua vez, pode e deve ser desnaturalizada.

A relação entre gênero e colonialidade apresentada por María Lugones (2008) também representa uma relevante contribuição. Para a autora, o gênero e a raça são "ficções poderosas", pois ao serem apresentadas por algumas teorias como construções sociais que consideram apenas as experiências e racionalidades norte-americanas e

\footnotetext{
9 O artigo "A categoria político-cultural de amefricanidade" foi originalmente publicado em Tempo Brasileiro. Rio de Janeiro, nº 92/93, (jan./jun.), 1988: 69-82.
} 
europeias, reproduzem o padrão de poder moderno/colonial. Consequentemente, tanto os homens, quanto as mulheres de distintas identidades étnico-raciais são inferiorizados nas diversas áreas da vida social, pois essas construções fictícias não reconhecem as especificidades de raça e gênero que se constituem em diferentes contextos (LUGONES, 2008: 94).

A pedagogia defendida por bell hooks (2013) possui ampla relação com a perspectiva anticolonialista, crítica e feminista. Nesse contexto, a autora pontua que a educação de crianças e jovens negras e negros é um compromisso político que deve estar relacionado à prática da liberdade:

A educação como prática da liberdade é um jeito de ensinar que qualquer um pode aprender. Esse processo de aprendizagem é mais fácil para aqueles professores que também creem que sua vocação tem um aspecto sagrado; que creem que nosso trabalho não é simplesmente partilhar informação, mas sim o de participar do crescimento intelectual e espiritual dos nossos alunos. Ensinar de um jeito que respeite e proteja as almas dos nossos alunos é essencial para criar as condições necessárias para que o aprendizado possa começar do modo mais profundo e mais íntimo (hooks, 2013: 24).

A pedagogia crítica de Paulo Freire influenciou significativamente a perspectiva de bell hooks, por evidenciar o caráter revolucionário que a educação pode assumir. A autora rememora uma passagem de Freire, na qual o autor admite que "não podemos entrar na luta como objetos para nos tomarmos sujeitos mais tarde" (hooks, 2013: 66). Assim, é possível inferir que todos(as) os(as) educandos(as), diante de uma educação crítica, libertadora e engajada, podem ter conhecimento de suas histórias para além do viés da colonialidade e se tornarem protagonistas das narrativas de suas vivências. Portanto, a educação não pode ser reduzida à "transferência de conteúdos" e o conhecimento não pode ser resumido "à pura informação", sem relação com as visões de mundo dos(as) educandos(as) (hooks, 2013: 11).

Assim, as proposições de bell hooks (2013) nos permite inferir que a relação entre a perspectiva anticolonialista, crítica e feminista podem superar os limites impostos pelos currículos influenciados pela colonialidade dos saberes e, desse modo, possibilitar reflexões inclinadas à elaboração de práticas pedagógicas que questionem "as parcialidades que reforçam os sistemas de dominação" (como o racismo e o cisheteropatriarcado) e proporcionem "novas maneiras de dar aulas a grupos 
diversificados de alunos" (hooks, 2013: 13). Contudo, a intenção por si só pode ser insuficiente, pois uma vez que o padrão da colonialidade recai sobre as áreas básicas da vida social, o mesmo ocorre com as formas de comportamento no ambiente escolar.

Visto que a maioria dos alunos aprende por meio de práticas educacionais tradicionais e conservadoras e só se interessa pela presença do professor, qualquer pedagogia radical precisa insistir em que a presença de todos seja reconhecida. Muitas vezes. antes de o processo começar, é preciso desconstruir um pouco a noção tradicional de que o professor é o único responsável pela dinâmica em sala. Essa responsabilidade é proporcional ao status. Fato é que o professor sempre será o principal responsável, pois as estruturas institucionais maiores sempre depositarão sobre seus ombros a responsabilidade pelo que acontece em sala de aula. [...] O entusiasmo é gerado pelo esforço coletivo (hooks, 2013: 17-18).

Tendo em vista que a escola é passível de reproduzir as formas de dominação que se manifestam na sociedade, também há papéis sociais que, nesse contexto, são hierarquizados. Isso implica dizer que as relações colonizadas constituídas no ambiente escolar determinam que a figura do(a) professor(a) é superior à do(a) estudante, e que outras formas de comportamento distintas desta tendem a ser deslegitimadas.

Para que uma proposta de pedagogia radical e, também, decolonial seja reconhecida como legítima, bell hooks (2013) considera que, além da insistência prática, é necessário demonstrar que a presença de cada sujeito envolvido(a) no processo de ensino e aprendizagem importa. Sendo assim, pedagogia radical inclui as perspectivas críticas e feministas e, nessa concepção, passa a incluir também um verdadeiro reconhecimento das diferenças - determinadas pela classe social, pela raça, pela prática sexual, pela nacionalidade etc. (hooks, 2013: 20).

Em suma, é importante reconhecer que as políticas públicas e educacionais devem ser um campo de proposições contra-hegemônicas à lógica capitalista moderna colonial. Contudo, essa disputa é complexa e gradual: não deve ser desconsiderada, mas deve ser compreendida como tal, tendo em vista que no Estado vigoram ainda os eixos de poder da colonialidade. Ainda que a decolonialidade dos saberes apresente desafios para a superação da lógica colonial, é possível considerar que o conhecimento sobre essa complexidade pode nos instrumentalizar a resistir às "estratégias de colonização" por meio de uma pedagogia radical (hooks, 2013) e decolonial (WALSH, 2013). 


\section{Considerações finais}

O presente artigo visou contextualizar como a colonialidade enquanto forma de poder incide nas diversas áreas da vida social, perpassando, inclusive, a constituição dos saberes escolares e a construção da identidade dos(as) educandos(as) a partir do eurocentrismo. Nesse sentido, buscou-se problematizar como o padrão de poder mundial eurocentrado também atinge as categorias de raça e gênero nos currículos escolares, ainda que a diversidade e a igualdade sejam versadas pelas legislações de políticas públicas e educacionais.

Torna-se imprescindível evidenciar que os currículos escolares são marcados pelas imposições do capitalismo moderno hegemônico em suas dimensões colonialistas. Sendo assim, há uma tendência de que o racismo epistêmico seja naturalizado pelos saberes escolares, comprometendo significativamente o aspecto democrático da educação, bem como a construção da identidade dos educandos enquanto sujeitos marcados pelas diversidades étnico-raciais, de gênero, dentre outras.

A fim de delinear proposições políticas do ponto de vista da decolonialidade dos saberes, objetivou-se apresentar algumas contribuições que a pedagogia decolonial e suas possíveis confluências podem oferecer para a elaboração de estratégias de resistência à colonialidade, à homogeneização da diversidade e à eurocentrização dos saberes no contexto da educação, sobretudo no que se refere às temáticas de raça e gênero.

Nesse sentido, as contribuições acerca da pedagogia radical apresentada por bell hooks (2013), fundamentada em uma perspectiva anticolonialista, crítica e feminista, bem como a proposta de pedagogia decolonial apresentada por Catherine Walsh (2013), somadas à interpretação de Lélia Gonzalez sobre as impressões do racismo e do sexismo na cultura brasileira e a metodologia interseccional (AKOTIRENE, 2019) nos permitem pensar que, mesmo em contextos de marginalização das formas de racionalidade e existência subalternizadas pelo colonialismo, é possível elaborar estratégias de resistência à colonialidade.

Estas estratégias de resistência envolvem a consciência e o conhecimento crítico sobre a complexidade histórica pela qual o projeto de capitalismo colonial/moderno e 
globalizado foi constituído, bem como o reconhecimento da realidade social dos(as) educandos(as) e do protagonismo que eles(as) possuem enquanto sujeitos (hooks, 1989) no processo de ensino e aprendizagem.

Nesse sentido, é fundamental analisar os limites, bem como as possibilidades que os conteúdos escolares podem oferecer para a formação dos(as) educandos(as) em uma perspectiva que possa desnaturalizar as "ficções" (LUGONES, 2008) que permeiam a categoria de raça, gênero, dentre outras, que são desvalorizadas pela racionalidade universalista da colonialidade de poder. Assim, considera-se que a divulgação de referenciais teóricos acerca da pedagogia decolonial pode substanciar tanto a formação e atuação de professores(as), quanto de educandos(as), além de possibilitar a efetivação de saberes e práticas pedagógicas como contrapartida ao eurocentrismo. Sobretudo, a divulgação das referências produzidas por intelectuais que assumem uma perspectiva decolonial e vivenciam os aspectos sociais que abordam em suas epistemologias podem propiciar aos(às) educandos(as) a noção de que a consciência crítica sobre os efeitos da modernidade colonial podem torná-los(as) sujeitos de suas (re)existências.

\section{Referências bibliográficas}

ADAMS, Telmo (2015). WALSH, Catherine (Ed.). Pedagogias decoloniais: práticas insurgentes de (re)existir y (re)vivir. Tomo I. Quito, Ecuador. Praxis Educativa, Ponta Grossa, vol. 10, n. 2: 585-590. Universidade Estadual de Ponta Grossa (UEPG). Disponível em: https://dialnet.unirioja.es/servlet/articulo?codigo=5167476. Acesso em: 05 mar. 2021.

AKOTIRENE, Carla (2019). Interseccionalidade. São Paulo: Pólen Livros.

BRASIL (1996). Lei n. 9.394, de 20 de dezembro de 1996. Estabelece as diretrizes e bases da educação nacional. Diário Oficial da República Federativa do Brasil. Disponível

em: https://www2.senado.leg.br/bdsf/bitstream/handle/id/529732/lei_de_diretrizes_e_ bases_1ed.pdf. Acesso em: 06 mai. 2020.

BRASIL (2003). Lei n. 10.639, de 9 de janeiro de 2003. Altera a Lei n. 9.394, de 20 de dezembro de 1996, que estabelece as diretrizes e bases da educação nacional, para incluir no currículo oficial da Rede de Ensino a obrigatoriedade da temática "História e Cultura Afro-Brasileira", e dá outras providências. Diário Oficial da República Federativa do Brasil. Disponível em: http://www.planalto.gov.br/ccivil_03/leis/2003/110.639.htm. Acesso em: $01 \mathrm{dez}$. 2020.

BRASIL (2008). Lei n. 11.645, de 10 de março de 2008. Altera a Lei n. 9.394, de 20 de dezembro de 1996 modificada pela Lei no 10.639, de 9 de janeiro de 2003, que estabelece as diretrizes e bases da educação nacional, para incluir no currículo oficial da rede de ensino a obrigatoriedade da temática "História e Cultura Afro- 
Brasileira e Indígena”. Diário Oficial da República Federativa do Brasil. Disponível em: http://www.planalto.gov.br/ccivil_03/_ato20072010/2008/lei/l11645.htm. Acesso em: 13 mar. 2021.

BRASIL (2013). Lei n. 12.852, de 5 de agosto 2013. Institui o Estatuto da Juventude e dispõe sobre os direitos dos jovens, os princípios e diretrizes das políticas públicas de juventude e o Sistema Nacional de Juventude - SINAJUVE. Diário Oficial da República Federativa do Brasil. Disponível em: www.planalto.gov.br/ccivil_03/_Ato2011-2014/2013/Lei/L12852.htm. Acesso em: 06 mai. 2020.

FERREIRA, Michele Guerreiro; SILVA, Janssen Felipe da (2018). Confluências entre pedagogia decolonial e educação das relações étnico-raciais: elementos de uma práxis curricular outra a partir das contribuições de Franz Fanon e Paulo Freire. In: GARCIA, Maria de Fátima; SILVA, José Antônio Novaes da (org.). Africanidades, afrobrasilidades e processo (des)colonizador: contribuições à implementação da lei 10.639/03. João Pessoa: Editora da UFPB: 74-113

GOMES, Nilma Lino (2003). Educação, identidade negra e formação de professores/as: um olhar sobre o corpo negro e o cabelo crespo. Educação e Pesquisa, São Paulo, vol. 29, n. 1: 167-182, jan./jun.

GONZALEZ, Lélia (2018). A categoria político-cultural de amefricanidade. In: (UCPA), União dos Coletivos Pan-Africanistas (org.). Primavera para as rosas negras. São Paulo: Editora Filhos da África: 321-334.

GONZALEZ, Lélia (2018). Por um feminismo afrolatinoamericano. In: (UCPA), União dos Coletivos Pan-Africanistas (org.). Primavera para as rosas negras. São Paulo: Editora Filhos da África: 307-320.

HENRIQUES, Ricardo (2001). Desigualdade racial no Brasil: evolução das condições de vida na década de 90. Rio de Janeiro: IPEA

hooks, bell (2013). Ensinando a transgredir: a educação como prática da liberdade. Trad. Marcelo Brandão Cipolla. São Paulo: Editora WMF Martins Fontes.

JACCOUD, Luciana; BEGHIN, Nathalie (2002). Desigualdades raciais no Brasil: um balanço da intervenção governamental. Brasília: IPEA.

KILOMBA, Grada (2019). Memórias da plantação: episódios de racismo cotidiano. Trad. Jess Oliveira. Rio de Janeiro: Cobogó.

LUGONES, María (2008). Colonialidad y Género. Tabula Rasa. Bogotá - Colombia, n. 9: 75-101, jul./dez. Disponível em: https://www.revistatabularasa.org/numero9/05lugones.pdf. Acesso em: 05 mar. 2021.

MALDONADO-TORRES, Nelson (2007). Sobre la colonialidad del ser: contribuciones al desarrollo de un concepto. In: CASTRO-GÓMEZ, Santiago.; GROSFOGUEL, Ramón. (Orgs.) El giro decolonial. Reflexiones para una diversidad epistémica más allá del capitalismo global. Bogotá: Universidad Javeriana-Instituto Pensar, Universidad Central-IESCO, Siglo del Hombre Editores: 127-167.

OLIVEIRA, Luiz Fernandes de; CANDAU, Vera Maria Ferrão (2010). Pedagogia decolonial e educação antirracista e intercultural no Brasil. Educação em Revista, Belo Horizonte, vol. 26, n. 1: 15-40, abr. FapUNIFESP (SciELO). Disponível em: https://www.scielo.br/scielo.php?pid=S010246982010000100002\&script=sci_abstract\&tlng=pt. Acesso em: 02 de fev. 2021.

PAIXÃO, Marcelo Jorge de P. (2006). Desigualdades raciais no Brasil; análise de indicadores quantitativos e qualitativos. Rio de Janeiro: Universidade Federal do Rio de Janeiro, Instituto de Economia. In: Debates do programa de ações afirmativas da Universidade Federal de São Carlos. 
QUIJANO, Aníbal (2005). Colonialidade do poder, eurocentrismo e América Latina. In: LANDER, E. (Org.). A colonialidade do saber: eurocentrismo e ciências sociais. Perspectivas latino-americanas. Buenos Aires: CLACSO: 117-142. Disponível em: http://biblioteca.clacso.edu.ar/clacso/sursur/20100624103322/12_Quijano.pdf. Acesso em: 05 mar. 2021.

QUIJANO, Aníbal (2009). Colonialidade do poder e classificação social. In: SANTOS, Boaventura de Sousa; MENESES, Maria Paula (orgs.). Epistemologias do Sul. Coimbra: Edições Almedina Sa: 73-118. Disponível em: https://ayalaboratorio.files.wordpress.com/2017/09/quijano-anibal-colonialidadedo-poder-e-classificac3a7c3a3o-social.pdf. Acesso em: 13 mar. 2021.

REIS, Toni; EGGERT, Edla (2017). Ideologia de gênero: uma falácia construída sobre os planos educacionais brasileiros. Educação \& Sociedade, Campinas, vol. 38, n. 138: 09-26, mar. Disponível em: https://www.scielo.br/scielo.php?script=sci_arttext\&pid=S010173302017000100009. Acesso em: 03 dez. 2020.

SARTRE, Jean-Paul (1968). Prefácio. In: FANON, Frantz. Os condenados da terra. Trad. José Laurênio de Melo. Rio de Janeiro: Civilização Brasileira S.A.: 03-21.

SILVA, Petronilha Beatriz G. (2007). Aprender, ensinar e relações étnico-raciais no Brasil. Educação, Porto Alegre, vol. 63, n. 3: 489-506, set./dez. Disponível em: https://revistaseletronicas.pucrs.br/ojs/index.php/faced/article/view/2745/2092 Acesso em: 02 dez. 2020.

WALSH, Catherine (2006). Interculturalidad y colonialidad del poder. Un pensamiento y posicionamiento "outro" desde la diferencia colonial. In: WALSH, C.; LINERA, A. G.; MIGNOLO, W. Interculturalidad, descolonización del estado y del conocimiento. Buenos Aires: Ediciones del Signo: 21-70.

WALSH, Catherine (2009). Desde Abya Yala: temas de interculturalidad crítica. Chiapas, México.

Artigo recebido em 14 de março de 2021.

Aprovado em 18 de junho de 2021.

DOI: $10.12957 /$ intellectus.2021.58400 